\title{
"INFLUENCE OF PARTICLE INDEX OF COARSE AGGREGATE AND ITS INFLUENCES ON PROPERTIES OF ASPHALT CONCRETE MIXTURES"
}

\author{
Anirudh N ${ }^{1}$, K.M.Mallesh ${ }^{2}$, Mohammed Ilyas Anjum ${ }^{3}$ \\ ${ }^{I}$ Post Graduate Student, Dept of Civil Engg. JNNCE, Shimoga, Karnataka, India \\ ${ }^{2}$ Associate Professor, Dept of Civil Engg, Siddaganga Institute of Technology, Tumkur \\ ${ }^{3}$ Professor, Dept of Civil Engg., Ghousia college of Engineering, Ramanagaram
}

\begin{abstract}
Mineral aggregate constitutes approximately $95 \%$ of hot mix asphalt by weight. The present study includes the determination of particle index based on fractured faces counts of coarse aggregate i.e. less than 2, more than or equal to 2 and more than 3 and its influences on marshall and fatigue properties of hot mix asphalt mixtures. The different particle index values ranging from 9 to 16 for the coarser size (19-13.2mm) have been determined and the same are used in the marshall mix design. The important factor for minimizing fatigue property of hot mix asphalt (HMA) mixture are, the fractured face count for coarse aggregate. The objective of the study is to evaluate the effect of particle index value on aggregate properties. Asphalt mix with crushed particles produces higher stability values with the increase in particle index value. The study also found that an increase in the amount of crushed particles causes decrease in unit weight and an increase in voids in mineral aggregate and optimum asphalt content. As fractured faces counts increases, the stiffness ratio (TSR) also increases. More the particle index value better will be the resistance to fatigue (Permanent deformation of the pavement).
\end{abstract}

Keywords: Particle index, fractured faces and Tensile strength ratio $* * *$

\section{INTRODUCTION}

Rapidly accelerating pace of construction of modern highways in the country calls for greater emphasis on the quality of construction not the least because, by and large, such projects are being undertaken by soft loans from international agencies and in such cases, generally, stricter regimes of quality assurance system are enforced.

Mineral aggregates constitute about $95 \%$ of HMA by weight. The mineral aggregate is made predominantly of coarse aggregates. Aggregates fractured face, particle shape and texture is the key parameter that influences on bitumen mixture properties. The properties of the aggregate have direct and significant effects on performance of asphalt pavements. Aggregate fractured face is one of the important properties that must be considered in the mix design of asphalt pavements to avoid premature pavement failure.

Aggregates constitute major part of the pavement structure. The engineering properties of the aggregates, as well as its shape (i.e. form and angularity) and texture, substantially affect the overall performance of the pavement. A number of researchers reported that form and surface texture of aggregates have significant effect on the mechanical property of the bituminous mixes, for example, shear resistance, durability, stiffness, fatigue resistance, rutting resistance, workability, bitumen demand etc. The present article briefly discusses the issues related to fractured face, aggregate shape and texture.

Particle Index, is a definite relationship was found to exist between the fractured face count and particle shape and texture of the coarse aggregate. Higher percentages of crushed particles increase the index of particle shape and texture significantly and also simultaneously increases the particle index value. An increase in the particle index value of aggregates leads to increase in the stability of the pavement there by reducing the permanent deformation of the pavement.

The fractured face, particle shape and texture play a vital role in the design and performance of bituminous concrete mixes. The MORT\&H for "Road and bridge works" has specified a minimum limit for stability and stiffness ratio is $900 \mathrm{~kg}$ and $80 \%$. When the fractured face of the aggregate improves then the stability and stiffness ratio increases. The aggregate shape factor mainly depends on the rock formation and the type of crusher being used for crushing the aggregates .The most commonly used crushers in India are jaw crushers, using which, it is difficult to get more fractured face aggregates.

The fractured face, particle shape and texture of aggregates are important physical properties of aggregates, which affect the 
quality of bituminous mixes. As most of the crushers in India Consists of primary jaw and secondary cone crushers and the fractured face decreases when the blades of crusher become older, due to the wear and tear of the blades during crushing operation. When the particle index decreases then there is a less interlocking property in between the aggregates tend to break during traffic operations. Hence there was a need to study the performance of bituminous mixes for increased fractured faces. Hence an attempt as been made to study the effect of fractured faces, particle shape and texture for different particle index.

Aggregates can either be natural or manufactured. Natural aggregates are generally extracted from larger rock formations through an open excavation (quarry). Usually the rock is blasted or dug from the quarry walls then reduced in size using a series of screens and crushers. Some quarries are also capable of washing the finished aggregate.

However, often there is a lack of consistency between the aggregate specifications and the ability to measure all the desired properties of aggregates. For example, the most common test methods for evaluating aggregate angularity and surface texture are indirect measures at best. Proper selection and evaluation of aggregate properties will remain necessary to produce high-quality asphalt concrete mixtures, particularly as traffic and loads increase. Quantification of aggregate properties with rational, objective characterization methods is desirable.

Visual examination is the most common method of judging aggregate shape, the main objective of this investigation is to explore the use of different aggregate shapes in bituminous concrete mixes. The performance of the aggregate shape factors is evaluated in terms of Marshall Stability test results and indirect tensile strength test results.

\subsection{Importance of the Problem Selected}

To large extent quality of road construction depends upon the quality of aggregates which impart structural strength to a finished pavement when compared to all physical properties of aggregates. Fractured faces of the aggregates dominate the quality of road construction. Fractured face is an important physical property of the aggregate. If the increase in fractured face counts of the aggregate it avoids the premature pavement failure. It has been shown by a number of investigations that presence of more fractured face of aggregates adversely affects the properties of bituminous mixes.

The properties of aggregates, in turn, are functions of the stratum of rock bed, type of rock being crushed, and ratio of feed opening size to product size and the methods adopted for crushing of the different physical properties of aggregates, fractured face, particle shape and texture properties dominate the quality of road construction, especially, where the strength of the pavement layer is derived from interlocking of aggregates.

Hence there is a need to find the effect of volumetric properties of the mixes, at different proportion of fractured faces like $<2,=2$ and $>3$ with different particle index of 9,12 , 14 and 16.

Elliot, Ford, Ghanim and Tu5 conducted an investigation to evaluate the effect of variations in the gradation of aggregates on the properties of asphalt concrete mixtures. The primary objectives were to determine the effect of gradation variation on (1) creep behavior as a measure of rutting resistance, (2) split tensile strength as an indicator of fatigue resistance potential, (3) Marshall mix properties as a measure of mix acceptability and (4) resilient modulus as a design parameter.

From this investigation, the authors concluded the following:

a) Gradation variations have the greatest effect when gradation changes in the general shape of the gradation curve (fine to coarse or coarse to fine).

b) Coarse to fine gradation variations produce the highest Marshall flow while fine to coarse gradation variation produced the lowest Marshall flow.

c) Creep stiffness is lowest for coarse to fine and fine to coarse gradation variations.

d) Marshall stability is affected by gradation variations, fine gradations produce highest stability and fine to coarse gradations produce the lowest stability.

e) Coarse gradation variations produce the lowest tensile strengths.

Herrin and Goetz conducted a laboratory evaluation to determine the effect of aggregate shape on the stability of asphalt concrete mixtures. This laboratory study involved crushed and uncrushed gravel, crushed limestone for the coarse aggregate, and natural sand and crushed limestone sand for the fine aggregate. In their tests, the strength of the mixture, regardless of the type of coarse aggregate, increased substantially when the fine aggregate was changed from rounded sand to crushed limestone. A major finding was that the strength of the asphalt mixture was affected more by a chance in the fine aggregate than a change in the coarse aggregate.

Wedding and Gaynor' 2 evaluated the effect of particle shape in dense graded asphalt concrete mixtures. The percentage of crushed and uncrushed coarse aggregates and the types of fine aggregate which included natural and washed concrete sands were varied in the mixtures. The analysis of the different aggregate blends was conducted on specimens produced by the Marshall procedure. The authors reached the following conclusions from this study.

a) Asphalt mixtures with crushed particles produced higher stability values than mixtures with uncrushed, rounded aggregates. 
b) The substitution of crushed gravel sand in place of natural sand increased the stability of the mixtures equivalent to the increase of adding 25 percent crushed coarse aggregate.

c) An increase in the amount of crushed particles caused a decrease in unit weight, and an increase in voids in mineral aggregate and optimum asphalt content.

Griffith and Kallas' 3'I4 conducted several laboratory evaluations that determined the effects of aggregate characteristics on asphalt mixtures. They studied the effect of aggregate type on voids and strength characteristics of asphalt concrete mixtures. The authors found that uncrushed gravel mixtures develop voids lower than the voids in crushed gravel mixtures at optimum asphalt contents. They also evaluated the influence of fine aggregates on the strength of asphalt concrete specimens. Various combinations of aggregate gradations using natural and crushed coarse aggregate and natural sand fine aggregate were analyzed. They found that an increase in angularity or crushed fines increased the Marshall and Hveem stability values at the optimum asphalt content. An increase in angularity in the fine aggregate also increased the minimum void percentages and increased the optimum asphalt contents.

Field15 conducted a study to determine the effect of variation of crushed aggregate percentages in asphalt concrete mixtures. He found that replacing uncrushed aggregates with crushed aggregates increased the stability and increased the void content and voids in mineral aggregate for a given asphalt content. The higher VMA values allow more asphalt in the mix which improves the durability of the asphalt concrete pavement.

\subsection{Objectives of the Study}

a) Marshall properties analysis at different particle index.

b) Moisture susceptibility damage estimation by ITS.

c) Pavement deformation analysis at fatigue test.

\subsection{Scope of the Work}

1. Determination of particle index according to ASTM D3398 by varying the percentage of different fractured faces $(<2,=2$ and $>3$ ).

2. To find out the $\%$ of uncompacted voids for the obtained particle index according to AASHTO T304.

3. Mix design is conducted for Bituminous Concrete Grade-II as per the MoRT\&H specifications.

4. Mechanical properties such as stability, flow and Indirect tensile strength test are conducted and the results are compared.

5. Fatigue test to evaluate the permanent deformation at different stress level.

\section{LABORATORY STUDIES}

Aggregates: Aggregate samples of sizes $20 \mathrm{~mm}$ down, $10 \mathrm{~mm}$ down and Quarry dust are collected from the crusher and sampled aggregates are characterized for the following properties.

Table 1: Physical properties of aggregates

\begin{tabular}{|c|c|c|c|}
\hline S1 No & Test & Result & $\begin{array}{c}\text { MoRT\&H specification } \\
\text { limits }\end{array}$ \\
\hline 1 & Aggregate Impact value & $25.7 \%$ & $27 \%$ max \\
\hline 2 & Los Angles Abrasion & $27.8 \%$ & $35 \% \max$ \\
\hline 3 & Aggregate Crushing value & $22 \%$ & $30 \% \max$ \\
\hline 4 & $\begin{array}{c}\text { Flakiness and Elongation } \\
\text { Index (combined) }\end{array}$ & $26.33 \%$ & $30 \% \max$ \\
\hline
\end{tabular}

Table 2: Specific gravity and water absorption of aggregates

\begin{tabular}{|c|c|c|c|}
\hline \multicolumn{2}{|c|}{ Size of aggregates } & Specific gravity & Water absorption \\
\hline $\begin{array}{c}\text { Passing } \\
\text { through IS } \\
\text { sieve (mm) }\end{array}$ & $\begin{array}{c}\text { Retained on IS } \\
\text { sieve (mm) }\end{array}$ & $\begin{array}{c}\text { (IS:2386, Part-3, } \\
1963)\end{array}$ & $\begin{array}{c}\text { (IS:2386, Part- 3, } \\
1963)\end{array}$ \\
\hline 19 & 12.5 & 2.66 & 0.6 \\
\hline
\end{tabular}




\begin{tabular}{|l|l|l|l|}
\hline 12.5 & 4.75 & 2.67 & 0.5 \\
\hline \multicolumn{2}{|c|}{ Dust } & 2.68 & 0.4 \\
\hline
\end{tabular}

Bitumen: Source of the Bitumen used for the project work is Mangalore Refineries and petrochemicals Ltd. (MRPL) and
Grade selected is 60/70.The bitumen is tested in the laboratory as per the procedure laid in the IS code:73.

Table 3: Properties of 60/70 (VG-30) bitumen

\begin{tabular}{|c|c|c|c|c|c|}
\hline Sl No & Test & Test method & Unit & Results & $\begin{array}{c}\text { Requirement as } \\
\text { MORTH }\end{array}$ \\
\hline 1 & Penetration & IS:1203-1925 & $\mathrm{mm}$ & 65 & $50-70$ \\
\hline 2 & Ductility & IS:1208-1978 & $\mathrm{cm}$ & 79 & Min 75 \\
\hline 3 & Specific gravity & IS :1202 & - & 1.01 & - \\
\hline 4 & Softening point & IS:1205-1978 & $0^{\text {c }}$ & 49 & Min 47 \\
\hline 5 & Flash point & IS :1209-1978 & $0^{\text {c }}$ & 276 & Min 220 \\
\hline
\end{tabular}

\subsection{Determination of Particle Index for different} Fractured Faces $(<2,>=2$ and $>3)$ of Coarse

\section{Aggregate (19mm-13.2mm)}

The combined effects of particle shape and surface texture of aggregates were determined in accordance with ASTM Test Method for Index of Aggregate Particle Shape and Texture (D 3398). The equipment required for this test consists of basically a cylindrical steel mould $152 \mathrm{~mm}(6 \mathrm{in}$.) in diameter by $178 \mathrm{~mm}(7 \mathrm{in}$.) high, and steel $\operatorname{rod} 16 \mathrm{~mm}(5 / 8 \mathrm{in}$.) in diameter by $610 \mathrm{~mm}$ (24 in.) long with the tamping end rounded to a hemispherical tip.

A clean, washed, oven-dried, single-size aggregate fraction was used for this test. The mould was filled in three equal layers, with each layer compacted with 10 well-distributed blows of the tamping rod. Each tamp consisted of a drop with the tamping rod from $51 \mathrm{~mm}$ (2in.) above the surface of the layer being compacted. This procedure was repeated using the same material but applying 50 blows on each of the three layers. The weight of the contents of the mould in each case was determined and the corresponding percentage of voids was calculated using the bulk specific gravity of each aggregate fraction.
The particle index $(P I)$ is derived using the following equation,

$$
P I=1.25 \mathrm{~V} 10-0.25 \mathrm{~V} 50-32.0
$$

Where

$\mathrm{V} 10$ = percent voids in the aggregate compacted with 10 blows per layer,

$\mathrm{V} 50=$ percent voids in the aggregate compacted with 50 blows per layer,

Calculated voids

Where

$$
\begin{aligned}
\mathrm{V} 10 & =[1-(\mathrm{M} 10 / \mathrm{sv})] \times 100 \\
\mathrm{~V} 50 & =[1-(\mathrm{M} 50 / \mathrm{sv})] \times 100
\end{aligned}
$$

M10 = Average mass of the aggregate in the mold compacted at 10 drops Per layer

M50 = Average mass of the aggregate in the mold compacted at 50 drops Per layer

$\mathrm{S}=$ Bulk-dry specific gravity of the aggregate size fraction

$\mathrm{V}=$ Volume of the cylindrical mold

Table 4: Obtained Particle Index by varying the $\%$ of different fractured faces

\begin{tabular}{|c|c|c|c|c|c|c|c|c|c|}
\hline \multirow{2}{*}{ S1 No } & \multirow{2}{*}{$\begin{array}{l}\text { M10 } \\
\end{array}$} & \multirow{g}{*}{$\begin{array}{l}\text { M50 } \\
(\mathrm{gm})\end{array}$} & \multirow{2}{*}{$\begin{array}{l}\text { V10 } \\
(\%)\end{array}$} & \multirow{2}{*}{$\begin{array}{l}\text { V50 } \\
(\%)\end{array}$} & \multicolumn{4}{|c|}{ Fractured Faces (\%) } & \multirow{2}{*}{ Particle Index } \\
\cline { 5 - 8 } & & & & & $<2$ & $=2$ & $<3$ & $>3$ & \\
\hline 1 & 4840 & 4968 & 41.13 & 39.57 & 100 & - & - & - & 9 \\
\hline 2 & 4630 & 4750 & 43.68 & 42.22 & 30 & 50 & - & 20 & 12 \\
\hline 3 & 4502 & 4784 & 45.24 & 41.81 & - & - & 60 & 40 & 14 \\
\hline 4 & 4365 & 4504 & 46.91 & 45.22 & - & - & 20 & 80 & 16 \\
\hline
\end{tabular}




\subsection{Uncompacted Void Content of Coarse Aggregate}

\section{Using Aashto T- 304}

Apparatus: Cylindrical mould, funnel, glass plate, weighing balance

Record the mass of the empty measure. Mix each test sample with the spatula until it appears to be homogeneous. Position the jar and funnel section in the stand and center the cylindrical measure with the axis of the funnel. Use a finger to block the opening of the funnel. Pour the test sample into the funnel. Level the material in the funnel with the spatula. Remove the finger and allow the sample to freely flow into the cylindrical measure. After the funnel empties, strike off excess from the top of the cylindrical measure by a single pass of the spatula with the width of the blade vertical, using the straight part of its edge in light contact with the top of the measure. Until this operation is complete, avoid vibration or disturbance that could cause compaction of the aggregate in the measure. Brush adhering grains from the outside of the cylindrical measure.

Calculate the uncompacted voids for obtained particle index according to the following formula:

Where:

$$
\mathrm{U}=((\mathrm{V}-(\mathbf{F} / \mathbf{G})) / \mathrm{V}) * \mathbf{1 0 0}
$$

$\mathrm{U}=$ uncompacted voids, in percent

$\mathrm{V}=$ volume of cylindrical measure

$\mathrm{F}=$ net mass of fine aggregate

$\mathrm{G}=$ bulk specific gravity (Gsb) of aggregate

Table 5: Determination of the uncomapacted voids for different Particle Index

\begin{tabular}{|c|c|}
\hline Particle Index & Uncompacted Voids \\
\hline 9 & 46.51 \\
\hline 12 & 49.61 \\
\hline 14 & 50.69 \\
\hline 16 & 53.62 \\
\hline
\end{tabular}

Aggregate Gradation: The gradation obtained using 19$12 \mathrm{~mm}, 12-4.75 \mathrm{~mm}, 4.75 \mathrm{~mm}$ stone dust along with MoRT\&H specified gradation is shown in fig below Figure
Gradation Curve obtained at JMF for the obtained Particle Index
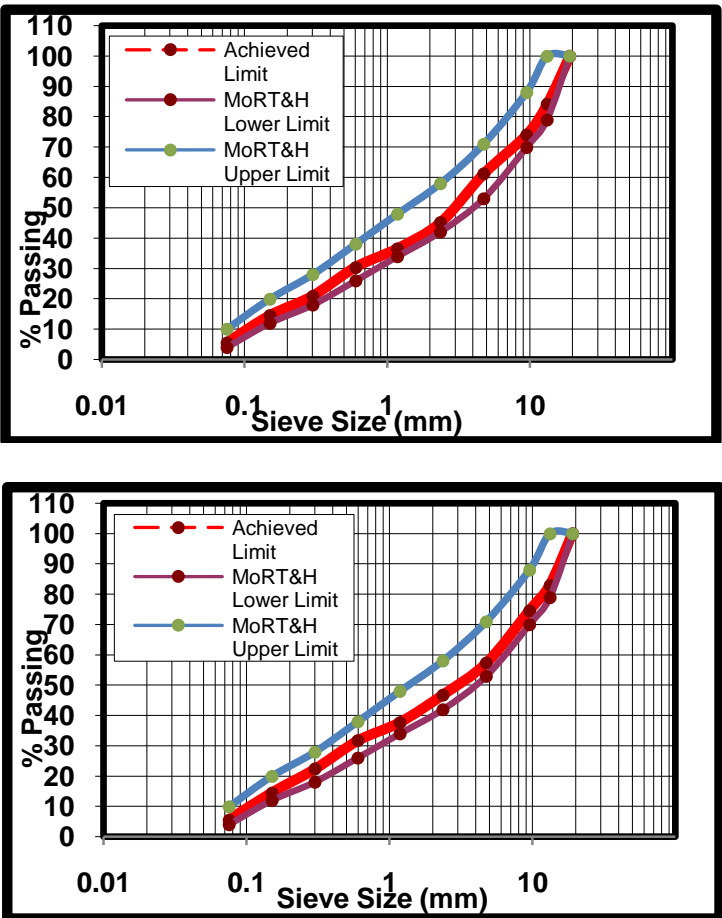

Fig 1 \& 2: Gradation curve for Particle Index 9 and 12
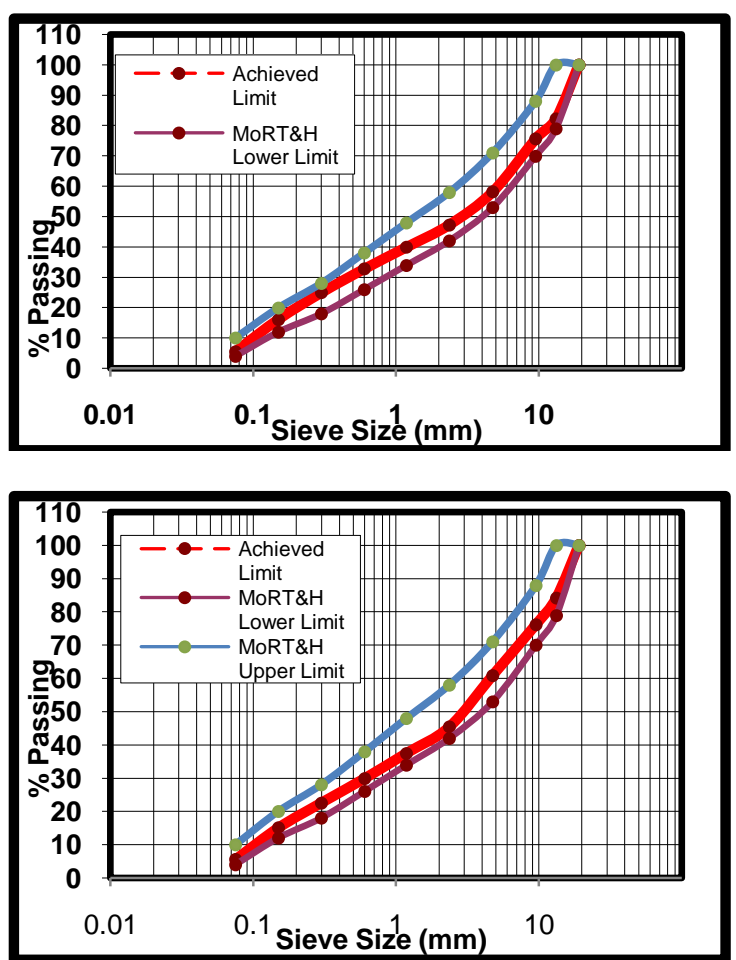

Fig 3 \& 4: Gradation curve for Particle Index 14 and 16 


\subsection{Marshall Method of Mix Design}

The principle of the Marshall stability is the resistance to plastic flow of cylindrical specimens of a bituminous mixture loaded on the lateral surface. It is the load carrying capacity of the mix at $60{ }^{\circ} \mathrm{C}$ and is measured in $\mathrm{KN}$. The desirable mix properties include stability, density, durability, flexibility, resistance to skidding and workability during construction. Mixture Designs will be performed using the Marshall method by preparing and compacting samples with Bitumen content varied in $0.5 \%$ increments according to "ASTM Test Method for Resistance to Plastic Flow of bituminous Mixtures Using Marshall Apparatus". Bituminous concrete gradation as per MORT\&H Specification is selected. Grade 60/70 Bitumen binder will be used. Specimens will be compacted with 75 blows on each side. Three samples will be made for each bitumen content. The optimum Bitumen content was chosen as the bitumen content that produced $4.5 \%$ air voids.
Marshall Graphs were plotted for air voids, VMA, VFB, Stability flow and density and Optimum binder content was determined for all the four cases of particle index. As per the guidelines of MS-2 Bitumen content corresponding to median of air voids percentage $(4.5 \%)$ is read from the graph and all other parameters are checked for that binder content so as to confirm that whether all other parameters such as VMA, VFB, Stability and flow falls within the MORT\&H specified limits. From the Experimental investigations for four different optimum binder contents i.e. 5.1, 5.18, 5.22 and 5.3 was obtained at $4.5 \%$ air voids for PI 9, PI 12, PI 14 and PI 16. A total of 9 Marshall Specimens, 3 specimens each were prepared at OBC for particle index 9, 12, 14 and 16 and tested for bulk density, stability, flow, air voids, VFB and VMA. The values along with the MORT\&H Specifications are given in Table 6 and 6.1.

Table 6 and 6.1: Physical properties of BC mix for various binder contents at different PI levels

\begin{tabular}{|c|c|c|c|c|c|c|c|c|c|c|c|c|}
\hline \multirow{2}{*}{ Properties } & \multicolumn{9}{|c|}{ Particle Index 9 } & \multicolumn{6}{c|}{ Particle Index 12 } \\
\cline { 2 - 13 } & 4.5 & 5 & 5.5 & 6 & 6.5 & 7 & 4.5 & 5 & 5.5 & 6 & 6.5 & 7 \\
\hline $\begin{array}{c}\text { Bulk } \\
\text { density } \\
\text { gm/cc) }\end{array}$ & 2.35 & 2.37 & 2.36 & 2.35 & 2.34 & 2.32 & 2.34 & 2.35 & 2.36 & 2.37 & 2.34 & 2.33 \\
\hline $\begin{array}{c}\text { Stability } \\
\text { (kg) }\end{array}$ & 1122.8 & 1272.4 & 1415.6 & 1512.8 & 1280.7 & 1175.1 & 1219.0 & 1346.5 & 1435.4 & 1673.5 & 1326.4 & 1160.8 \\
\hline $\begin{array}{c}\text { Flow } \\
(\mathrm{mm})\end{array}$ & 1.55 & 2 & 2.46 & 3.02 & 4.56 & 5.23 & 2.15 & 2.41 & 3.14 & 3.59 & 4.22 & 4.92 \\
\hline $\begin{array}{c}\text { Air } \\
\text { Void(\%) }\end{array}$ & 5.7 & 4.7 & 3.81 & 3.5 & 3.16 & 3.26 & 6.09 & 4.95 & 3.8 & 2.66 & 3.16 & 2.84 \\
\hline VMA (\%) & 16.25 & 15.98 & 16.78 & 17.57 & 18.37 & 19.5 & 16.62 & 16.7 & 16.8 & 16.88 & 15.21 & 19.14 \\
\hline VFB (\%) & 64.92 & 70.58 & 77.29 & 80.07 & 82.8 & 83.28 & 63.35 & 70.35 & 77 & 84.24 & 81.63 & 85.21 \\
\hline
\end{tabular}

Table 7: Mix Properties for varying particle index

\begin{tabular}{|c|c|c|c|c|c|c|c|c|c|c|c|c|}
\hline \multirow{2}{*}{ Properties } & \multicolumn{6}{|c|}{ Particle Index 14} & \multicolumn{6}{|c|}{ Particle Index 16} \\
\hline & 4.5 & 5 & 5.5 & 6 & 6.5 & 7 & 4.5 & 5 & 5.5 & 6 & 6.5 & 7 \\
\hline $\begin{array}{c}\text { Bulk } \\
\text { density } \\
(\mathrm{gm} / \mathrm{cc})\end{array}$ & 2.33 & 2.35 & 2.37 & 2.37 & 2.36 & 2.34 & 2.33 & 2.34 & 2.35 & 2.34 & 2.32 & 2.30 \\
\hline $\begin{array}{c}\text { Stability } \\
(\mathrm{kg})\end{array}$ & 1295.9 & 1426.3 & 1625.3 & 1517.3 & 1421.2 & 1306.1 & 1439.9 & 1662.2 & 1874.8 & 1787.8 & 1530.4 & 1438.3 \\
\hline Flow (mm) & 2.06 & 2.32 & 2.93 & 3.21 & 3.83 & 4.6 & 2.11 & 2.33 & 2.75 & 3.16 & 3.47 & 4 \\
\hline $\begin{array}{c}\text { Air Voids } \\
(\%)\end{array}$ & 6.48 & 4.95 & 3.41 & 2.66 & 2.33 & 2.42 & 6.5 & 5.3 & 4.22 & 3.88 & 3.9 & 3.23 \\
\hline $\operatorname{VMA}(\%)$ & 16.97 & 16.7 & 16.44 & 16.88 & 17.67 & 18.88 & 16.98 & 17 & 17.14 & 17.93 & 19.06 & 19.33 \\
\hline VFB (\%) & 62 & 70.35 & 79.25 & 84.24 & 86.81 & 87.12 & 61.71 & 68.82 & 75.37 & 78.3 & 79.11 & 83.29 \\
\hline
\end{tabular}




\begin{tabular}{|c|c|c|c|c|c|}
\hline \multirow{2}{*}{ Properties } & \multicolumn{4}{|c|}{ Particle Index } & \multirow{2}{*}{ MORTH Specification } \\
\hline & 9 & 12 & 14 & 16 & \\
\hline OBC $\%$ & 5.1 & 5.18 & 5.22 & 5.3 & Min 5 \\
\hline Bulk density $(\mathrm{gm} / \mathrm{cc})$ & 2.37 & 2.362 & 2.358 & 2.346 & - \\
\hline Stability $(\mathrm{kg})$ & 1300 & 1540 & 1630 & 1810 & $900 \mathrm{~kg}$ \\
\hline Flow $(\mathrm{mm})$ & 2 & 2.4 & 2.5 & 2.6 & $2-4$ \\
\hline Air Voids (\%) & 4.3 & 4.6 & 4.8 & 5 & $3-6$ \\
\hline VFB $(\%)$ & 71.2 & 72.5 & 74 & 75 & $65-75$ \\
\hline VMA $(\%)$ & 16 & 16.5 & 16.7 & 17 & Min 16 \\
\hline
\end{tabular}

\subsection{Indirect Tensile Strength}

Test was conducted for varying particle index i.e., on all 4 types of aggregates are tabulated in the Table 8.The ASTM T283 code specifies 80 percent should be the minimum value of Indirect Tensile Strength ratio. In the following Table 8 only the aggregates of \% of using more fractured faces particle index 14 and 16 satisfies the requirement.

Table 8: Indirect tensile strength test results

\begin{tabular}{|c|c|c|c|c|}
\hline \multirow{2}{*}{ SL.NO } & \multirow{2}{*}{ PI } & ITS $\left(\mathbf{K N} / \mathbf{m}^{\mathbf{2}}\right)$ & ITS $\left(\mathbf{K N} / \mathbf{m}^{\mathbf{2}}\right)$ & \multirow{2}{*}{ ITS ratio } \\
\cline { 3 - 4 } & 9 & $\begin{array}{c}\text { Conditioned } \\
\text { specimen }\end{array}$ & $\begin{array}{c}\text { unconditioned } \\
\text { specimen }\end{array}$ & \\
\hline 1 & 12 & 7.4 & 10.3 & 71.84 \\
\hline 2 & 14 & 8.42 & 11.01 & 76.47 \\
\hline 3 & 16 & 10.1 & 11.8 & 85.43 \\
\hline 4 & & 11.4 & 12.5 & 91.2 \\
\hline
\end{tabular}

\subsection{Fatigue Life Cycle for different Particle Index}

Test was conducted for different stress ratios $0.6,0.7$ and 0.8 for all four types particle index

Table 9: Fatigue cycle results for different particle index

\begin{tabular}{|c|c|c|c|}
\hline SI No & Particle Index & Stress level in \% & No of cycle \\
\hline \multirow{3}{*}{1} & \multirow{3}{*}{9} & 60 & 1080 \\
\hline & & 70 & 738 \\
\hline & & 80 & 378 \\
\hline \multirow{3}{*}{2} & \multirow{3}{*}{12} & 60 & 1140 \\
\hline & & 70 & 774 \\
\hline & & 80 & 480 \\
\hline \multirow{3}{*}{3} & \multirow{3}{*}{14} & 60 & 1214 \\
\hline & & 70 & 835 \\
\hline & & 80 & 549 \\
\hline \multirow{3}{*}{4} & \multirow{3}{*}{16} & 60 & 1309 \\
\hline & & 70 & 918 \\
\hline & & 80 & 611 \\
\hline
\end{tabular}




\section{ANALYSIS OF TEST RESULTS AND DISSCUSSION}

\subsection{Relation b/w Bulk Density v/s Binder Content}

Here Particle Index is evaluated by varying crushed faces of aggregates. If the crushed faces of aggregate are more it significantly increases the particle index value. An increase in the amount of crushed particles caused a decrease in bulk density. This may be due to the $\%$ of voids increases with increase in the particle index.

At Optimum Binder content of $5.1 \%$ for PI 9 Bulk density achieved is $2.37 \mathrm{gm} / \mathrm{cc}$. Similarly at $5.18 \%$ OBC for PI 12 Bulk density is $2.362 \mathrm{gm} / \mathrm{cc}, 5.22 \%$ OBC for PI 14 Bulk density is $2.358 \mathrm{gm} / \mathrm{cc}$ at $5.3 \%$ OBC for PI 16 Bulk density of $2.346 \mathrm{gm} / \mathrm{cc}$ is obtained. Figure 5.11 clearly indicates the decrease in Bulk density with increase in the Particle Index.

\subsection{Relation $b / w$ Stability v/s Binder content}

The Marshall stability is a measure of the mass viscosity of the asphalt mixture and is controlled by the angle of internal friction of the aggregate and the viscosity at $60{ }^{\circ} \mathrm{C}$ of the asphalt binder. Stability value increases with the increase in Particle Index. This is clearly indicated in the graph. Stability of the Marshall specimen at Particle Index 16 is found to be very high. The minimum Stability requirement of $900 \mathrm{~kg}$ is achieved for different Particle Index i.e. PI 9, PI 12 and PI 14 but the stability values are very much less compared to values obtained at PI 16. Asphalt mixtures with crushed particles produced higher stability values than mixtures with uncrushed, rounded aggregates. Hence even though there is an increased percentage of Binder for PI 9, PI 12 and PI 14 stability increases with the increase in Particle Index.

\subsection{Relation b/w \% Air Voids $\left(V_{a}\right)$ v/s Binder Content}

Optimum Binder content is found to be $5.1 \%$ For Particle Index 9 at median of air voids i.e. $4.5 \%$. Similarly $5.18 \%, 5.22$ and $5.3 \%$ Binder content is obtained at $4.5 \%$ air voids. The mixture air void range is used to ensure enough asphalt binder to provide a durable pavement, but not so much that the pavement will deform under loading or have excess asphalt binder flushing or bleeding on the surface. An increase in the amount of crushed particles caused an increase in the voids in mineral aggregate and optimum binder content. This indicates that with the increase in the Particle Index of aggregates there is an increase in the percentage of voids and binder content. Even though it is found satisfying the specification requirement of 3-6\% air voids for all the four different levels of particle index.

\subsection{ITS Ratio v/s Particle Index}

The average indirect tensile strength ratios are $71.84 \%$, $76.47 \%, 85.43 \%$ and $91.2 \%$ for particle index of PI 9, PI 12 ,
PI 14 and PI 16.The Specimens with increased particle index i.e. PI 14 and PI 16 fulfill the minimum criteria of $80 \%$ as per the ASTM standards. The indirect tensile strength ratios for PI 9 and PI 12 is less than $80 \%$ so it requires anti-stripping additives may be required to increase the indirect tensile ratios. It states that higher the crushed faces of the aggregates improves the durability of the pavement, less crushed faces of the aggregates are moisture sensitivity material.

\subsection{Fatigue Cycle v/s Particle Index}

Fatigue test is conducted to know the behavior of the pavement. In this study fatigue test is conducted for three different stress ratios i.e., $60 \%, 70 \%$ and $80 \%$ for four different particle indexes i.e., PI 9, PI 12, PI 14 and PI 16. Fatigue cycle increases with increase in the particle index. Crushed faces of the aggregate increases then it increases the interlocking properties of the aggregates and it develops the proper bonding between aggregates and bitumen, so higher the crushed faces of the aggregates resist the cracks on pavement by excessive loading of the vehicle. It states that the crushed faces of the aggregates play a vital role in the performance of pavement. When there are more crushed faces it resists to the deformation of pavement.

\section{CONCLUSIONS}

Laboratory experiments were conducted on four types of aggregates selected. The tests on mechanical properties, Marshall Stability, indirect tensile test and fatigue tests were conducted and the following conclusions are drawn based on the laboratory investigation.

1. Generally more number of fractured face count $(>2)$ is one among the physical requirements of the aggregates used in bituminous course or surface course. In the laboratory determination of particle index concluded that more fractured face count results in more particle index value ie. PI 9, PI 12, PI 14 and PI 16.

2. The Marshall method of mix design and the OBC (optimum binder content) arrived have revealed that more the fractured faces more the $\mathrm{OBC}$ ie. $5.1 \%$ for PI 9, 5.18\% for PI 12, 5.22\% for PI 14 and $5.3 \%$ for PI 16 and this may be attributed to the coating requirements of the rough texture which is increased due to the fractured faces of the aggregates.

3. Trend line analyses have shown that there is a definite relation between the Marshall properties and the binder content. In all the four cases of the particle index $\mathrm{R}$ squared value is found to be more than 0.85 . This confirms that fractured faces of the aggregates do have influence on the performance of the bituminous mixtures.

4. The Marshall stability shows an increase in trend line as the particle index value increases. This reveals that there is a strong resistance by the aggregates against 
the fatigue cracking or permanent deformation rutting.

5. An increase in the more fractured faces of the aggregates indicates the decrease in the unit weight of the bituminous mixture in the study. This is due to the higher end of the OBC ie. 5.3\% for PI 16.

Besides more $\mathrm{OBC}$ value also increases the voids filled with bitumen and voids in mineral aggregates for more PI value. This is due to the expelling of the more bitumen content under the compaction. However this doesn't much affect the performance of the pavement.

6. The Indirect tensile strength ratios indicated that the less particle index value are much more susceptibility for the moisture than the higher particle index values.

7. The fatigue test conducted at different stress level indicates that resistance is found more for the higher value of the particle index. This may be due to the internal readjustment of the particles, maintaining the proper interlocking property or existence of the cohesiveness among the aggregates due to the rough texture. Hence this clear states that more the fractured faces never allow the sliding or moving of the aggregates under the wheel loads.

8. The comprehensive performance studies such as permanent deformation or workability and still exhaustive laboratory investigation with quite a good number of aggregate particle index value may conclude the optimization such that the optimized particle index value should fulfill all the bituminous mixture requirements both at the lab during experimental stages and at the field after laying and allowing the traffic.

\section{REFERENCES}

[1] ASTM :D3398-00,Standarad test method for index of aggregate particle shape and texture

[2] Jian-Shiuh Chen, K.Y. Lin and M.K. Chang (2004) Influence of coarse aggregate shape on the strength of asphalt concrete mixtures, Journal of the Eastern Asia Society for Transportation Studies, Vol. 6, pp. $1062-$ 1075

[3] Kandhal, P. S., Motter, J. B., and Khatri, M. A. Evaluation of Particle Shape and Texture:Manfuctured Versus Natural Sands. Transportation Research Record 1301.

[4] Huang, E. Y. An Improved Particle Index Test for the Evaluation of Geometric Characteristic of Aggregates. American Society for Testing and Materials Journal of Material, Vol. 2, Number 1,march, 1967.

[5] Kandhal, P. S., Khatri, M. A., and Motter, J. B. Evaluation of Particle Shape and Texture of mineral Aggregates and Their Blends. Journal of the Association of Asphalt paving Technologies, Vol 61, 1992.
[6] M. Herrin and W.H. Goetz. Effect of Aggregate Shape on Stability of Bituminous Mixes, Proc. HRB, VO1.33, 1954.

[7] F. Field. The Importance of Percent Crushed in Coarse Aggregate as Applied to Bituminous pavements Proc. AAPT, Vol.27, 1958.

[8] J.M. Grifilth and B.F. Kallas. Aggregate Voids Characteristics in Asphalt Paving Mixes Proc HRB, VO1.36, 1957.

[9] G.W. Maupin. Effect of Particle Shape and Surface Texture on the Fatigue Behavior of Asphaltic Concrete. Highway Research Record, No.313, 1970.

[10] P.A. Wedding and R.D. Gaynor. The Effects of Using Crushed Gravel as the Coarse and Fine Aggregate in Dense Graded Bituminous Mixtures. Proc. AAPT, Vol. 30, 1961.

\section{BIOGRAPHIES}

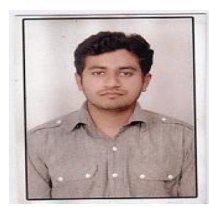

Ani.rudh $\mathrm{N}$ is currently working as a Assistant Professor in Jawaharlal Nehru National College of Engineering in Department of Civil Engineering. He has completed his Post-graduation degree in Transportation Engineering \& Management from Siddaganga Institute of Technology, Tumkur.

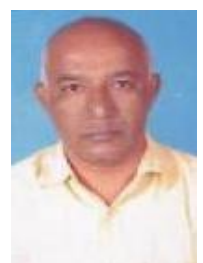

Mallesh $\mathrm{K} \mathrm{M}$ is currently working as Associate Professor in Siddaganga Institute of Technology in Civil Engineering Department. $\mathrm{He}$ is having a more than 30 years experience in the teaching field and also 5years experience in Highway field. He is also senior Material Engineer in KNR Constructions and he is doing Third party Inspection for PMGSY and Suvarna Grama Road projects.

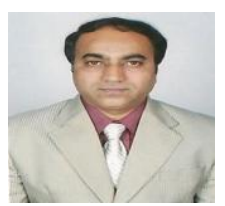

Dr Mohamed Ilyas Anjum is currently working as Vice - Principal \& HoD Civil in Ghousia College of Engineering is having a more than 30 years experience in the teaching field. 